\title{
O papel da experiência na aprendizagem: perspectivas na busca e no uso da informação
}

\author{
The role of experience in the learning: perspectives in \\ information seeking and use
}

Kelley Cristine Gonçalves Dias GASQUE'

\section{RESUMO}

Este artigo discute a importância da experiência na construção de novos conhecimentos, destacando a evolução histórica do conceito e o seu papel na aprendizagem, bem como no desenvolvimento de competências para buscar e usar informações para a produção de conhecimento científico. Parte do pressuposto de que, quanto mais experiência de qualidade os pesquisadores adquirirem com a busca e uso da informação, maior será o impacto no conhecimento produzido. Considera que a consciência da experiência pode ser uma forma de tornar o ser humano responsável eticamente pelo ciclo de produção científica, visto que as modificações ou transformações propiciadas pela ciência ocorrem em um mundo inseparável do ser, parte do corpo humano em que a mente se insere. Por isso, a discussão sobre experiência envolve os aspectos cognitivos e a dimensão ética de como o homem se relaciona com a natureza e a transforma.

Palavras-chave: busca e uso da informação; experiência; ética; letramento informacional; conhecimento científico, aprendizagem.

\begin{abstract}
This article discusses the relevance of experience to the construction of new knowledge, emphasizing the historical evolution of this concept and its role in the learning process, as well as in the development of seeking and using information for the production of scientific knowledge. The basic hypothesis is that the more qualified in managing information is the acquired experience of researchers, the more important can be the impact to the produced knowledge. It also considers that the conscience of experience may also be a way for human being to become ethically responsible for the cycled process of scientific production, since the modification or transformation of science happens in an inseparable world of being, part of the human body in which the mind is inserted. As a result, the discussion on experience involves the cognitive aspects and the ethical dimension of the ways man is related to nature and his capacity of transforming it.
\end{abstract}

Keywords: information seeking and using; experience; ethics; informational literacy; scientific knowledge; learning.

INTRODUÇÃO

Ciência, informação, conhecimento, aprendizagem e experiência são conceitos interdependentes. A ciência é constituída por um corpo de conhecimentos validado pelos pesquisadores, resultante da aprendizagem humana mediante a busca e o uso da informação e da utilização de metodologias

1 Doutora em Ciência da Informação pela Universidade de Brasília. Brasília, DF, Brasil. E-mail: < kelleycristinegasque@hotmail.com>. Recebido em 18/6/2007 e aceito para publicação em 17/3/2008. 
próprias. Dessa forma, para a produção de conhecimentos científicos, é necessário o engajamento deles em processos de aprendizagem que englobam tanto os conhecimentos do objeto de estudo quanto as atividades de busca e de uso da informação.

Durante muitos anos, a preocupação com as questões referentes à busca e ao uso da informação permeou principalmente o discurso da biblioteconomia e da ciência da informação, mas começa a se expandir para outras áreas acadêmicas. Com a constatação de que a informação e o conhecimento crescem de forma cada vez mais acelerada, o significado do saber mudou, pois "em vez de lembrar e repetir informações, a pessoa deverá ser capaz de encontrá-las e usá-las" (Simon, 1996 apud Conselho..., 2007, p.21).

Conseqüentemente, a busca e o uso da informação são atividades necessárias à produção do conhecimento científico e demandam per se competências ${ }^{2}$, cujo desenvolvimento requer formação específica, denominada Letramento Informacional. Por isso, parece não ser mais admissível ignorar que a ciência da informação precise também lidar cada vez mais diretamente com a aprendizagem, uma vez que pretende gerenciar a informação para torná-la acessível às pessoas.

Diversas teorias de aprendizagem têm sido elaboradas ou aperfeiçoadas para promover o aprimoramento pessoal e os progressos social, cultural e econômico. O comitê de desenvolvimento da Ciência da Aprendizagem (2007), sob supervisão do Conselho Nacional de Pesquisa dos Estados Unidos, identificou três descobertas com sólida fundamentação de pesquisas que apresentam importantes implicações à aprendizagem, nomeadamente: a experiência, a base de conhecimento factual e a metacognição.

Em relação à experiência, foco deste estudo, reconhece-se, na visão contemporânea da aprendizagem, que as pessoas elaboram novos conhecimentos a partir das experiências e vivências de mundo. $O$ sentido das coisas surge das atividades permanentes de intercâmbio de uma mente com um corpo que vive em um ambiente. Assim, as idéias e o conhecimento científico resultam de esquemas de pensamentos preliminares e de interação atenta entre o sujeito e o mundo, no qual ele busca e usa informações para construir conhecimentos. Nessa perspectiva, podese afirmar, então, que a ciência é produto do sujeito e de seu inter-relacionamento com o mundo, como assegura Merleau-Ponty (1999, p.3):

Tudo aquilo que sei do mundo, mesmo por ciência, eu o sei a partir de uma visão minha ou de uma experiência de mundo sem a qual os símbolos da ciência não poderiam dizer nada. Todo o universo da ciência é construído sobre o mundo vivido, e se queremos pensar a própria ciência com rigor, apreciar exatamente seu sentido e seu alcance, precisamos despertar essa experiência do mundo da qual ela é expressão segunda.

Pressupõe-se, então, que quanto mais experiência os pesquisadores adquirirem com a busca e uso da informação, maior será o impacto no conhecimento produzido. A consciência da experiência pode ser uma forma de tornar o ser humano responsável eticamente pelo ciclo de produção científica, visto que as modificações ou transformações propiciadas pela ciência ocorrem em um mundo inseparável do ser, parte do corpo humano, no qual se insere a mente. Por isso, a discussão sobre experiência envolve os aspectos cognitivos e a dimensão ética de como o indivíduo se relaciona com a natureza e a transforma.

Considerando-se, então, a importância da experiência na construção de conhecimentos e competências, será aqui focalizada, especificamente, a evolução histórica do conceito e o seu papel na aprendizagem e, conseqüentemente, na formação e no desenvolvimento de competências para buscar e usar informações na produção de conhecimentos científicos.

\section{RAZÃO E EXPERIÊNCIA: RAÍZES HISTÓRICAS}

Sem a pretensão de aprofundamento nas questões histórico-filosóficas, é oportuno apresentar um breve cenário em que se inscrevem os conceitos de razão e experiência, que, historicamente, opõem-se na cultura ocidental. A razão, fundada na especulação matemática e filosófica, relaciona-se à capacidade de

\footnotetext{
${ }^{2}$ Competências são "modalidades estruturais da inteligência, ou melhor, ações e operações que utilizamos para estabelecer relações com e entre objetos, situações, fenômenos e pessoas que desejamos oferecer". Exame Nacional do Ensino Médio - INEP (www.inep.gov.br).
} 
pensar, formar julgamentos, tirar conclusões. A experiência, instituída na tentativa e no erro, não era passível de produzir conhecimento verdadeiro.

Etimologicamente, o termo razão é derivado do latim ratio, que possui o significado de cálculo, conta, e foi concebido como o sinal distintivo da humanidade a partir da definição de homem como animal racional, proposta por Aristóteles. A "descoberta" da razão pelos gregos, entre os séculos VIII a.c. e VI a.c., sinaliza a transição do mítico para a racionalidade na história do pensamento ocidental. Até então, a humanidade estava impregnada pelo mito (mythos), conhecimento derivado das narrativas inspiradas pelos deuses, por forças naturais, histórias e crenças populares, que continha a verdade por ele mesmo, dispensando toda a prova.

$\mathrm{Na}$ Escola de Mileto, surgiram os primeiros pensadores, Thales (624-562 a.c.), Anaximandro (61 1 546 a.c.) e Anaxímenes (586-526 a.c), que tentaram explicar o mundo, utilizando a razão como forma de conhecimento. Posteriormente, Sócrates (469-399 a.c.), Platão (428/7-347 a.c.) e Aristóteles (384-322 a.c.) consolidaram a ruptura com o mito, ao enfatizarem que o conhecimento verdadeiro deveria ser mediado pela razão e não pela opinião (doxa), incapaz de garantir a verdade por ser própria do senso comum e das sensações. Nesse caso, a oposição entre logos/ episteme e doxa representou outro marco que destacava a importância da razão. A episteme, uma nova forma de racionalidade própria da ciência e da filosofia, apoiava-se na separação entre o discurso do sujeito e o objeto do conhecimento, devendo o conhecimento ser alicerçado na racionalidade, discurso e demonstração (Vasconcellos, 2003).

Na idade moderna, ocorreu a cisão entre a filosofia - considerada meramente especulativa ou reflexiva -, e a razão - decorrente do experimentalismo ou método matemático -, ou seja, o domínio do sujeito versus o domínio do objeto, da medida, da precisão. Após muitos séculos de pensamento especulativo e racional, Bacon, precursor da filosofia empíricopositivista, propôs que, para se chegar à verdade, era preciso a observação da natureza e a experimentação ${ }^{3}$ guiadas pelo raciocínio indutivo. Esse retorno à experiência como forma de obtenção do conhecimento, pela amplitude e características, refletiu sobre a filosofia, estabelecendo as bases para os empiristas e os racionalistas, seus opositores. E, por fim, os pragmatistas, instrumentalistas ou experimentalistas, que buscavam reconciliar as posições entre a experiência e a razão (Teixeira, 1959).

empirismo, teoria filosófica que admite a experiência como origem do conhecimento, considerava a prática como elemento fundamental, pois se reconhecia que, em tempos imemoriais, anteriores ao dualismo razão/experiência, muitos feitos da humanidade, como a domesticação de animais, confecção de ferramentas e instrumentos e a própria organização social foram adquiridos dessa maneira (Durozoi; Roussel, 1999). O racionalismo, ao contrário, entende o conhecimento como procedente, a priori, do conhecimento de princípios. Distinguem-se dois tipos de racionalismo: o absoluto (Platão, Descartes), que praticamente não deixa lugar nenhum à experiência, e o racionalismo crítico de Kant, que vincula a razão a uma experiência pré-definida e organizada (Durozoi; Roussel, 1999).

No final do século XIX, impulsionado pelas descobertas biológicas, surgiu o pragmatismo, termo cunhado por Peirce, William James e John Dewey. Tal movimento pretendia ser uma superação do racionalismo e do empirismo, a partir do desenvolvimento do conceito de experiência como interação do organismo vivo com o meio, no qual a psicologia buscava explicar o comportamento humano face à experiência e ao conhecimento (Teixeira, 1959).

E mais adiante, a fenomenologia, estudo descritivo dos fenômenos, inspirada em Husserl (18591938), consolida a idéia de que a realidade do sujeito e a dos objetos exteriores constituem o ponto de partida para a construção do conhecimento, considerando a perspectiva contingencial, ampliando o espaço para as discussões sobre o vivido. Um dos autores influenciados por essa corrente, Merleau-Ponty (19081961), "descreve a relação intencional que une o sujeito - encarnado e em situação histórica - às coisas e ao outro" (Durozoi; Roussel, 1999, p.322).

Enfim, a despeito da discussão crescente em torno da razão e da experiência, ainda parece predominar a racionalidade dicotômica, em que o homem tende a colocar as coisas em um pêndulo que

\footnotetext{
3 A experimentação seria a produção voluntária da experiência para obtenção de um resultado ou conhecimentos novos, processo visto como separado do sujeito (Teixeira, 1959).
} 
oscila pelos extremos, tornando remota uma conexão de equilíbrio. Historicamente, a razão sobressaiu-se em detrimento da experiência, como se fosse possível desvinculá-las. Quando a humanidade perceber plenamente que a razão e o corpo estão inextricavelmente coligados a um meio físico por meio de interações sucessivas que permitem o conhecer e o dar-se conta de estar conhecendo, será possível uma mudança de mentalidade calcada em uma profunda ética planetária.

\section{EXPERIÊNCIA: RESSIGNIFICANDO O CONCEITO}

Como se pode observar pelo histórico, a partir de fins do século XVIII, alguns filósofos como Kant, Husserl, Dewey, Merleau-Ponty e, mais recentemente, nas últimas décadas, com as descobertas das ciências cognitivas, pesquisadores como Varela, Thompson e Rosch discutiram a experiência, visando resgatar, em menor ou maior grau, o seu papel como fonte de conhecimento.

A experiência de uma pessoa constrói-se a partir dos perigos que enfrenta, processo que pode torná-la perita (Ortega y Gasset, 1973). Essa idéia só é possível quando existe estreita coordenação entre a mente e o corpo. A experiência é uma forma de perceber e interagir "atentamente" com o mundo, por meio da presença da mente em si mesma, o tempo suficiente para se obter insights sobre sua própria natureza e funcionamento (Varela; Thompson; Rosch, 2003). Dessa maneira, "buscar a essência do mundo não é buscar aquilo que ele é em idéia, uma vez que o tenhamos reduzido a tema do discurso, é buscar aquilo que de fato ele é para nós antes de qualquer tematização". Assim, "o mundo é aquilo que percebemos" (MerleauPonty, 1999, p. 13-14).

conceito de experiência sustenta-se em três noções fundamentais: linguagem, atenção consciente e interação corpo/mente e ambiente. A primeira, a linguagem, segundo Teixeira (1955), possibilita a transposição do ser biológico para o intelectual e social, compelindo-o a integrar os costumes, crenças, instituições, expressões e símbolos no comportamento, de acordo com a percepção dos significados e sentidos comuns das palavras em suas relações e conexões com as pessoas e coisas.

A segunda noção, a atenção consciente, diz respeito ao fenômeno pelo qual uma quantidade limitada de informações é processada ativa e conscientemente. Em geral, o ser humano realiza muitas atividades simultaneamente, evento conhecido como atenção dividida. Tal situação torna-se possível devido à automatização de algumas tarefas, por exemplo, dirigir e conversar com o acompanhante ou assistir à TV, observar as crianças estudando e falar ao telefone ao mesmo tempo. Quando a mente realiza várias atividades concomitantemente, ou não centra a atenção na atividade desenvolvida, pode-se distanciar do momento vivido e perscrutar outros tempos e memórias. Assim, a experiência mecânica, sem atenção ou significado, é diferenciada da atenta - atividade realizada reflexivamente. Desse modo, a experiência implica a atenção consciente, isto é, ela não é a lembrança de tudo o que ocorreu, de todas as atividades realizadas ou automatizadas, mas o que decorre da vivência consciente.

A interação corpo, mente e ambiente sustentase em várias pesquisas que demonstram a ocorrência entre eles. Estudos recentes sobre o cérebro, por exemplo, identificaram a produção da consciência como parte do mundo da matéria. Contudo, de acordo com o neurocientista Damásio (2004, p.225), “a idéia é menosprezada com freqüência, se é que se pode dizer que chega a ser considerada". O dualismo cartesiano, concepção que percebe a mente como uma essência não-física, separada de um corpo e uma realidade física, ainda não foi totalmente "exorcizado".

A experiência insere-se em um sistema, no qual se pode atribuir estruturas cerebrais específicas a todas as formas de comportamentos e experiências e, inversamente, mudanças na estrutura cerebral manifestam-se nos comportamentos e experiências. A estrutura cognitiva de um indivíduo reflete a relação de interdependência entre a estrutura mental e as experiências e comportamentos que se processam em um contexto específico, no qual as crenças e práticas biológicas, sociais e culturais condicionam essas experiências (Varela; Thompson; Rosch, 2003).

A idéia do mundo constituído do ponto de vista experiencial rompe radicalmente com a independência do sujeito em relação ao ambiente e vice-versa, pois nem um nem outro preexistem à interação. Essa concepção denominada de enativa (teoria da atuação), elaborada por Varela (2003), sugere que a cognição não consiste em representações do cérebro do observador construídas de um mundo predeterminado em relação a ele. Pelo contrário, o processo cognitivo 
é visto como uma construção dinâmica do mundo e, portanto, inseparável do histórico de vida, do processo de viver.

Dewey ([1910]1979) considerava a experiência fundamental na construção da cognição. Contudo, o foco principal do seu pensamento é a ênfase no relacionamento entre experiência, reflexão crítica e aprendizagem. $\bigcirc$ referido autor acreditava na existência de uma conexão orgânica entre educação e experiência, apoiada sobre o conhecimento relevante, o qual modifica a perspectiva, a atitude e competência do indivíduo (Dewey, 1979a).

○ conceito de experiência não se explica por si mesmo, pois "nada na experiência é absolutamente simples, singelo e isolado. Tudo o que foi experimentado acontece em união com outro objeto, qualidade ou acontecimento" e pode ser compreendido por meio de dois princípios fundamentais que atuam e interagem entre si - interação e continuidade. $\bigcirc$ primeiro remete à relação entre as condições objetivas e condições internas - mundo e mente -, e o segundo, à idéia de que todas as experiências se sustentam na anterior e modificam a ulterior (Dewey, 1979a, p.48).

De inspiração hegeliana e darwiniana, a experiência possui o sentido de vivência, Erlebnis, resultado da interação atenta e consciente entre o sujeito e o mundo, e de Erfahrung, experiência social, coletiva, histórica. Dessa maneira, não se processa apenas dentro do corpo e mente das pessoas, mas em um contexto específico. Esse movimento de mão dupla, denominado interação, baseia-se na suposição de que as condições ambientais modelam a experiência presente do sujeito que se reflete no meio ambiente, isto é, "há interação entre o indivíduo e objetos e outras pessoas" (1979b, p.36). Dewey exemplifica que as experiências de uma criança nascida em meio rural diferem daquelas de uma criança nascida na cidade e que as experiências dessas pessoas "mudam de algum modo as 'condições objetivas' em que as experiências passam" (1979b, p.31).

O segundo princípio refere-se à continuidade que pode estimular ou não novas experiências, em que as modificações ocorrem e afetam a qualidade das subseqüentes. Didaticamente, pode-se interromper esse continuum para averiguar quais são as experiências trazidas pelo aprendiz, de forma a facilitar outras conexões que se vincularão a outras e, assim, sucessivamente. Pressupõe-se que os indivíduos possuem bagagem cognitiva, afetiva e atitudinal, oriunda da sua vivência, que deve ser avaliada para constituir a base para novas inferências e, dessa maneira, proporcionar às pessoas novas experiências, a partir daquelas que possuem e que permitam a ligação com as subseqüentes.

No processo de aprendizagem, quando os seres humanos se deparam com um problema, inicialmente buscam uma experiência análoga para se orientar e facilitar a aquisição do novo conhecimento. Este, por sua vez, inicia-se a partir das experiências passadas armazenadas na memória que oferece conhecimentos úteis, de onde se originam as idéias. A inferência é entendida como o "processo de chegar a uma idéia do que está ausente na base do que está presente" por intermédio da sugestão do que é visto e lembrado. Isso dependerá primeiro da experiência pessoal e, conseqüentemente, do estado geral de cultura da época. Ressalte-se que "ninguém é capaz de pensar em alguma coisa sem experiência e informação sobre ela" (Dewey, 1979a, p.42).

Dewey assegura, ao longo de seu trabalho, que a experiência está intimamente vinculada à reflexão "que nos liberta da influência cerceante dos sentidos, dos apetites, da tradição" (1979 a, p. 199), de tal forma que se diferencia da mera atividade. Para o autor, por exemplo, não há experiência quando a criança coloca o dedo na chama, a qual surge quando o movimento é associado à dor sentida e ao entendimento que colocar o dedo no fogo provoca queimadura. A parte cognitiva da experiência é a existência da percepção das relações entre os fenômenos. Então, são possíveis dois tipos de experiência: tentativa e erro e a reflexiva, em que se utiliza o erro para melhorar.

A relação entre experiência e aprendizagem parece ser intensa. Ausubel (c1980, p.93) enfatiza a vinculação entre a aquisição de conceitos e o conjunto de experiências relevantes, em especial na primeira infância, momento em que "os conceitos refletem o impacto cumulativo da experiência imediata, empíricoconcreta, durante um grande período de tempo". Kant admitia a experiência como ponto de partida para a construção do conhecimento, contudo considerava que "se todo conhecimento começa com a experiência, isso não prova que ele derive por inteiro da experiência" (Durozoi; Roussel, 1999, p.178). Quanto a essa questão, parece haver certa concordância com as idéias de Dewey (1979a), ao demonstrar que, no processo de 
reflexão, as pessoas recorrem às experiências passadas como fontes de sugestões a serem analisadas juntamente com outras informações à luz dos argumentos que as apóiam.

Schön (2000, p. 16), ao investigar a teoria de Dewey para sua tese de doutorado, propôs, no âmbito da formação profissional, a interação entre teoria e prática por meio da reflexão para resolver os problemas que, muitas vezes, apresentam-se como "estruturas caóticas e indeterminadas". A reflexão sobre a experiência permite desenvolver, compreender e aprimorar a aprendizagem e o conhecimento, assim como avaliar os "entendimentos incompletos, às crenças falsas e às interpretações ingênuas dos conceitos que os aprendizes trazem consigo sobre determinado assunto" (Conselho..., 2007, p.27).

Alguns estudos apresentam evidências sobre o impacto da experiência na construção do conhecimento. Um exemplo é o de Bartlett (1932 apud Sternberg, 2000) em que se apresenta a característica construtiva da memória, fenômeno psicológico no qual uma pessoa constrói lembranças, com base nas suas experiências anteriores e expectativas, que podem afetar o modo como outra informação será armazenada. Nesse experimento, o pesquisador, ao solicitar aos indivíduos ingleses que aprendessem uma lenda norteamericana estranha e difícil de entender, observou que, para tornar a história mais compreensível para si próprios, eles distorciam sua evocação, sugerindo que a experiência prévia afeta como e o que lembramos.

Os seres humanos estão em um movimento permanente de aprendizagem por meio de construções e transformações que realizam em si, modificando continuamente o seu modo de conhecer, refletir, proceder e se comportar, como conseqüência de sua interação atenta com o mundo. Todas essas vivências, partes da história do indivíduo, ao se entretecerem com as dos outros, criam o conhecimento e a ciência. Entretanto, para que o conhecimento avance, deve estar registrado e acessível à comunidade. Os membros da comunidade, por sua vez, precisam desenvolver as competências necessárias para buscar e usar informações, visando à construção de novos conhecimentos, reiniciando continuamente o ciclo de produção científica.

\section{A EXPERIÊNCIA EA BUSCA E USO DA INFORMAÇÃO}

Buscar e usar a informação constituem competências cruciais na sociedade da aprendizagem.
A busca da informação relaciona-se ao modo como as pessoas procuram as informações que atendam às suas necessidades. Envolve a busca ativa ou passiva da informação, planejamento, estratégias e motivação para atingir objetivos, monitoração de estratégias, conhecimento e definição de canais ou fontes de informação potenciais, competências para usar tecnologias da informação e avaliação desse processo. O uso da informação compõe-se de atividades em que o indivíduo se engaja para apreender a informação e transformá-la em conhecimento. Compreende habilidades intelectuais como decodificação, interpretação, controle e organização do conhecimento. A decodificação e a interpretação, por sua vez, incluem atividades de leitura, estabelecimento de relações entre o conhecimento prévio e as novas informações, comparação de vários pontos de vista e avaliação. Controle e organização relacionam-se propriamente à organização da informação por meio do uso de instrumentos cognitivos como resumos, esquemas, mapas conceituais e elaboração de textos.

O desenvolvimento dessas competências abrange, também, valores pessoais, motivações, crenças, visão crítica e atitudes como responsabilidade, ética e, ainda, a capacidade do indivíduo de refletir, controlar e monitorar os próprios processos de busca e de uso da informação. Por isso, essas atividades implicam quase sempre a aprendizagem de um conteúdo que pode ser conceitual (fatos, situações, conceitos), procedimental (procedimentos, habilidades, destrezas, técnicas) ou atitudinal (postura, valores, comportamentos). Isso, por sua vez, pode resultar em um aumento do conhecimento pessoal.

O processo de construção e desenvolvimento das competências de busca e de uso da informação, Information Literacy, é fundamental para se viver em uma época de rápidos avanços tecnológicos e de propagação de grandes quantidades de informação em que se suscitam questionamentos sobre a sua autenticidade, validade e confiabilidade. As competências para manejar a informação ao longo da vida acadêmica parecem ser a base para a aprendizagem permanente. Assim, o letramento informacional é necessário a todas as disciplinas, ambientes de aprendizagem e níveis de educação (Association..., 2000).

Segundo Dudziak (2003), a expressão information literacy surgiu em 1974, no relatório intitulado The information service environment relationships and priorities. Nesse relatório, o 
bibliotecário americano Zurkowski apud Dudziak (2003) recomendava um movimento nacional em direção ao letramento informacional como ferramenta para acesso à informação. Contudo, de acordo com o documento Information Literacy Competency Standards for Higher Education, foi o ano de 1989 que marcou as iniciativas nos Estados Unidos da América, com uma publicação na qual se apresenta a definição dos elementos que compõem o letramento informacional, o papel educacional das bibliotecas acadêmicas e a importância dos programas educacionais para a capacitação dos estudantes (Association..., 2000).

Em 1990, foi fundado o National Forum on Information Literacy (NFIL) com a coalizão de mais de 75 membros entre instituições de educação, negócios e organizações governamentais. O objetivo foi conscientizar sobre a importância da questão e das atividades de orientação para a aquisição de competências. Em 1998, a American Association of School Librarians (AASL) e Association for Educational Communications and Technology (AECT) publicaram - Information Standards for Student Learning, detalhando as competências e indicadores a serem desenvolvidos pelos estudantes da educação básica. Assim sendo, desde 1989, muitos estados, escolas, universidades e instituições têm incentivado a aquisição de competências para lidar com a informação.

No Brasil, as discussões sobre a questão precisam ser intensificadas, principalmente no âmbito da educação básica, uma vez que a escola, de maneira geral, não tem contemplado em seu currículo o desenvolvimento das competências para buscar e usar a informação. Mesmo na universidade, lócus de ensino, pesquisa e extensão, parece haver pouca preocupação em sistematizar um programa de aprendizagem com esses conteúdos integrados aos conteúdos conceituais da área de estudo específica, extensivo ao corpo docente e discente. Especialmente na pós-graduação, em que os alunos devem apresentar uma dissertação e tese no final dos cursos de mestrado e doutorado, é inevitável, durante a pesquisa, a apreensão de algumas habilidades para produção do conhecimento científico.

Nesse contexto, percebe-se a importância da experiência na busca e no uso da informação ao se realizarem questionamentos do tipo: por que as pessoas buscam primeiramente as fontes ou canais de informações que thes estão mais próximos, em detrimento, às vezes, da sua qualidade? (Gasque, 2003;
Giacometti 1990; Kremer, 1981). Por que as pessoas usam mais especificamente um tipo de fonte ou canal de informação? Por que as pessoas usam pouco as bibliotecas? Por que a percepção que as pessoas possuem do próprio conhecimento influencia o processo de busca da informação? (Wilson, 1997). Outros questionamentos podem ser levantados e, de uma forma ou de outra, a experiência está envolvida tanto no sentido daquilo que foi vivido quanto no que será vivenciado pelo indivíduo.

Um exemplo de estudo que demonstra a relação entre a busca e o uso da informação e a experiência e o conhecimento foi conduzido pela Biblioteca Nacional de Medicina. A pesquisa utilizou a técnica do incidente crítico para avaliar o impacto do banco de dados MEDLINE sobre os usuários. O objetivo era descobrir o comportamento que orientava para o sucesso ou fracasso em resolver o problema. Os pesquisadores descobriram três pontos determinantes: 1) a motivação para pesquisar no MEDLINE na ocasião; 2) o impacto da informação obtida sobre o processo de tomada de decisão; 3) o último impacto da informação sobre os resultados da situação que motivou a busca (Wilson et al., 1989 apud Hewins, 1990). A pesquisa mostra que o sucesso dos resultados da busca pode interferir nas atividades subseqüentes e na própria percepção dos pesquisadores sobre como avaliam suas competências para buscar e usar a informação.

Outro exemplo é o estudo de Kremer (1981), em que foi testada a hipótese de que a percepção que os engenheiros têm a respeito da acessibilidade, facilidade de uso, qualidade técnica e experiência prévia determina o grau de uso do canal de informação. Os resultados apontaram que esses itens determinam significativamente a escolha de um canal; que o grau de experiência prévia conscientiza os engenheiros a respeito da acessibilidade, facilidade de uso e qualidade técnica de um canal; e que a freqüência de uso é motivada pela percepção da qualidade técnica de um canal e pelo grau de experiência prévia que os engenheiros tiveram com ele.

Os seres humanos são vistos como indivíduos conduzidos por objetivos que buscam informações ativamente. Chegam à educação formal e, posteriormente, à graduação, com crenças, conhecimentos prévios e experiências que influenciam suas percepções sobre o ambiente e como organizam e interpretam essas percepções, pois eles, na maioria das vezes, não têm 
oportunidade de sistematizar o conhecimento apropriado para se engajarem nas atividades de busca e de uso da informação. Diante dessas evidências, investimentos em programas educacionais para o desenvolvimento dessas competências com a mediação de profissionais competentes tornam-se imperativos.

Nesse sentido, sugere-se a adoção de uma abordagem multidisciplinar que transcenda uma concepção especializante e fragmentadora, que geralmente reduz a responsabilidade formativa dessa área somente à classe bibliotecária ou aos profissionais da ciência da informação. Isso implica, portanto, o compartilhamento das responsabilidades educativas entre as várias áreas do conhecimento, especialmente aquelas concernentes aos profissionais da educação — professores e pesquisadores — uma vez que estão diretamente envolvidos na luta por uma sociedade mais justa e solidária.

Tais programas devem ser sistematizados no próprio currículo, em uma perspectiva mais globalizante, ou seja, vinculados às diversas áreas de conhecimento. Outro ponto importante diz respeito ao favorecimento da compreensão e das possibilidades transformadoras da experiência pelos estudantes. De acordo com Giroux (1997), a experiência deve ser tão relevante na aprendizagem quanto problemática e crítica, porquanto é necessário que se reconheçam suas implicações políticas e morais. Por isso, o desenvolvimento de uma visão crítica deve transcender o discurso, pois parece existir certo estreitamento cognitivo quando se ignoram as questões do tipo: "por que estamos fazendo o que estamos fazendo? Por que este conhecimento está sendo aprendido?" (Giroux, 1997, p.81) O autor enfatiza que os estudantes devem compreender o relacionamento entre a teoria e os fatos, "principalmente porque a teoria representa a estrutura conceitual que medeia os seres humanos e a natureza objetiva da realidade social mais ampla" Giroux, 1997, p.82).

As estruturas teóricas atuam como filtros por meio dos quais as pessoas vêem as informações, selecionam fatos, definem e desenvolvem soluções para os problemas. Não se pode ignorar que existe um processo ideológico subjacente às nossas crenças e sistemas de valores. Nesse sentido, deve-se avaliar a própria estrutura teórica ou visão de mundo, pois, se existe a compreensão de um elo "entre os fatos e valores, então a questão de como a informação é selecionada, arranjada e seqüenciada para construir e interpretar uma visão da realidade assume uma dimensão axiomática" (Giroux, 1997, p.83).

Essas questões refletem a necessidade de se repensar a própria escola, visto que vários aspectos como a concepção de ensino e aprendizagem, a formação de professores, o currículo e a estrutura estão vinculados entre si. Nessa perspectiva, o conhecimento é produto de um arcabouço conceitual contextualizado e significativo, das relações derivadas da experiência humana e das atividades de busca e de uso da informação, como também da visão crítica do sujeito a partir da sua consciência como sujeito ético, parte da teia da vida. Aqui, evidencia-se a visão da concepção sistêmica, enraizada na idéia de interligação ecológica de todos os eventos que ocorrem na Terra, da qual a humanidade faz parte (Capra, 2001).

\section{CONCLUSÃO}

As discussões propostas nesse artigo evidenciam, mesmo de forma circunstancial, a importância da valoração da experiência na aprendizagem, na orientação das atividades usuais de pensamento e ação e também como subsídio para a reflexão, a responsabilidade e a ética. Elas asseguram que a racionalidade não deve ser privilegiada em detrimento da experiência, uma vez que a

\footnotetext{
Experiência opõe-se à razão, mas também a supõe e a inclui. Para um ser totalmente desprovido de inteligência, nenhum fato traria experiência, já que não the ensinaria nada. E um raciocínio para nós não passa de um fato como outro qualquer. Assim, nunca saímos da experiência; é o que dá razão ao empirismo e lhe veda ser dogmático (Comte-Sponville, 2003, p.232).
}

Essas idéias demonstram que a questão entre experiência e aprendizagem relaciona-se às conexões entre as experiências. Se elas forem desligadas podem não se articular entre si, mesmo que sejam agradáveis ou estimulantes. Na verdade, os alunos "têm e passam por experiências [...]. O problema não é a falta de experiências, mas o caráter dessas experiências habitualmente más e defeituosas, sobretudo do ponto 
de vista de sua conexão com futuras experiências" (Dewey, 1979b, p.16).

Reforça-se que a educação precisa considerar a produção do conhecimento como um processo mais amplo, relacionado às experiências e às reflexões do sujeito e em sintonia com a própria sociedade. Esta, por sua vez, exige de seus membros competências que possibilitem a inserção e adaptação contínua desse indivíduo na sociedade do conhecimento, a partir de seu engajamento nas atividades de busca e uso da informação. Como afirmava Wiener (1973), na década de 60, a eficiência dos seres humanos depende da sua maneira de se relacionar com o "bombardeio de informações".

Por fim, não se pode deixar de ressaltar a natureza complexa da questão, considerando-se que a experiência pessoal é constituída em determinado contexto ou circunstância em que o indivíduo e o próprio meio se modificam mutuamente. Nesse processo de transformação permanente, é preciso desenvolver visão crítica e ética para que o conhecimento científico seja colocado a favor da humanidade como instrumento de bem-estar, como sugere a Declaração sobre Ciência e o Uso do Conhecimento Científico (Conferência...., 1999). Essa moção, que leva em conta o grau de crescente interdependência entre os seres humanos e os sistemas de preservação da vida global de todas as espécies, adverte e convoca "as nações e os cientistas do mundo a reconhecer a urgência do uso do conhecimento de todos os campos da ciência de uma maneira responsável para satisfazer as necessidades e aspirações humanas sem o uso errado deste conhecimento".

\section{REFERÊNCIAS}

ASSOCIATION OF COLLEGE AND RESEARCH LIBRARY (EUA). Information literacy competency for higher education. Chicago: ALA, 2000.

AUSUBEL, D.P.; NOVAK, J.D.; HANESIAN, H. Psicologia educacional. 2.ed. Rio de Janeiro: Interamericana, c1980.

CAPRA, F. A teia da vida: uma nova compreensão científica dos sistemas vivos. 6.ed. São Paulo: Cultrix, 2001.

CONFERÊNCIA MUNDIAL SOBRE A CIÊNCIA: Ciência para o Século XXI: um Novo Compromisso, 1999, Budapeste. Declaração sobre ciência e o uso do conhecimento científico. Brasília: Ministério da Ciência e Tecnologia - MCT, 1999. Disponível em: $<$ http://ftp.mct.gov.br/Temas/budapeste/declaracao.htm > . Acesso em: 08 nov. 2006.

COMTE-SPONVILLE, A. Dicionário filosófico. São Paulo: Martins Fontes, 2003

CONSELHO NACIONAL DE PESQUISA DOS ESTADOS UNIDOS. Comitê de Desenvolvimento da Ciência da Aprendizagem. Comitê de Pesquisa da Aprendizagem e da Prática Educacional. Comissão da Educação e Ciências Sociais e do Comportamento; organização de J.D. Brasdorf; A.L. Brown; R.R. Cocking. Como as pessoas aprendem: cérebro, mente, experiência e escola. São Paulo: Senac, 2007.

DAMÁSIO, A.R. O erro de descartes. São Paulo: Companhia das Letras, 2004.

DEWEY, J. Como pensamos: como se relaciona o pensamento reflexivo com o processo educativo: uma reexposição. 4.ed. São Paulo: Nacional, 1979a.
DEWEY, J. Experiência e educação. São Paulo: Nacional, 1979b.

DUDZIAK, E.A. Information literacy: princípios, filosofia e prática. Ciência da Informação, v. 32, n. 1, p.23-35, 2003.

DUROZOI, G.; ROUSSEL, A. Dicionário de filosofia. 3.ed. Campinas, SP: Papirus, 1999.

GASQUE, K.C.G.D.; COSTA, S.M.S. Comportamento dos professores da educação básica na busca da informação para formação continuada. Ciência da Informação, v.32, n.3, p.54-61, 2003. Disponível em: <http://www.ibict.br/cionline/ viewarticle.php?id=52\&layout $=h t m l>$. Acesso em: 11 dez. 2005.

GIACOMETTI, M.M. Motivação e busca da informação pelo docente-pesquisador. Ciência da Informação, v. 19, n.1, p.1220, 1990.

GIROUX, H.A. Os professores como intelectuais. Porto Alegre: Artmed, 1997.

HEWINS, E.T. Information need and use studies. Annual Review of information Science and Technology, v.25, p.145-172, 1990.

KREMER, J.M. Fatores que afetam a escolha de um canal de informação. Revista Escola de Biblioteconomia da UFMG, v. 10, n. 1, p.53-66, 1981.

MERLEAU-PONTY, M. Fenomenologia da percepção. São Paulo: Martins Fontes, 1999.

ORTEGA Y GASSET, J. O homem e sua gente. Rio de Janeiro: Ibero-Americana, 1973. 
SCHÖN, D.A. Educando o profissional reflexivo: um novo design para o ensino e aprendizagem. Porto Alegre: Artmed, 2000.

STERNBERG, R.J. Psicologia cognitiva. Porto Alegre: Artmed, 2000

TEIXEIRA, A. Bases da teoria lógica de Dewey. Revista Brasileira de Estudos pedagógicos, v.23, n. 57, p.3-27, 1955.

TEIXEIRA, A. Filosofia e educação. Revista Brasileira de Estudos pedagógicos. v.32, n.75, 1959. p.14-27.
VARELA, F.; THOMPSON, E.; ROSCH, E. Amente incorporada: ciências cognitivas e experiência humana. Porto Alegre: Artmed, 2003.

VASCONCELLOS, M.J.E. Pensamento sistêmico: o novo paradigma da ciência. Campinas: Papirus, 2003.

WIENER, N. Cibernética e sociedade: o uso humano de seres humanos. São Paulo: Cultrix, 1973.

WILSON, T. Information behaviour: an interdisciplinary perspective. Information processing \& management, v.33, n.4, p.551-572, 1997. 